\title{
The non-gibberellic acid-responsive semi-dwarfing gene uzu affects Fusarium crown rot resistance in barley
}

Guangdeng Chen ${ }^{1,2,3}$, Wei Yan ${ }^{1,4}$, Yaxi Liu ${ }^{1,2}$, Yuming Wei ${ }^{2}$, Meixue Zhou ${ }^{5}$, You-Liang Zheng ${ }^{2}$, John M Manners ${ }^{1}$ and Chunji Liu ${ }^{1,6^{*}}$

\begin{abstract}
Background: Studies in Arabidopsis show that DELLA genes may differentially affect responses to biotrophic and necrophic pathogens. A recent report based on the study of DELLA-producing reduced height (Rht) genes in wheat and barley also hypothesized that DELLA genes likely increased susceptibility to necrotrophs but increased resistance to biotrophs.

Results: Effects of uzu, a non-GA (gibberellic acid)-responsive semi-dwarfing gene, on Fusarium crown rot (FCR) resistance in barley were investigated. Fifteen pairs of near isogenic lines for this gene were generated and assessed under two different temperature regimes. Similar to its impacts on plant height, the semi-dwarfing gene uzu also showed larger effects on FCR severity in the high temperature regime when compared with that in the low temperature regime.

Conclusions: Results from this study add to the growing evidence showing that the effects of plant height on Fusarium resistances are unlikely related to DELLA genes but due to direct or indirect effects of height difference per se. The interaction between these two characteristics highlights the importance of understanding relationships between resistance and other traits of agronomic importance as the value of a resistance gene could be compromised if it dramatically affects plant development and morphology.
\end{abstract}

Keywords: Plant height, Fusarium crown rot, uzu gene, Near isogenic lines, DELLA proteins

\section{Background}

One of the critical considerations in cereal breeding is the selection of reduced height $(R h t)$ genes. This is because different $R h t$ genes do not only affect height differently but may also have different effects on other morphological and agronomic traits of importance [1,2]. It is known that different $R h t$ genes can confer dwarfism by different mechanisms. Two of the most widely used $R h t$ genes in wheat, $R h t-B 1 b$ and $R h t-D 1 b$, are known to encode DELLA proteins which repress GA responsive growth. They are thought to confer dwarfism by producing constitutively active forms of these growth repressors

\footnotetext{
* Correspondence: chunji.liu@csiro.au

${ }^{1}$ CSIRO Plant Industry, 306 Carmody Road, St Lucia QLD 4067 Australia

${ }^{6}$ School of Plant Biology, The University of Western Australia, Perth, WA 6009, Australia

Full list of author information is available at the end of the article
}

[3]. Rht8, however, is not due to defective GA biosynthesis, but to a reduced sensitivity to brassinosteroids [4].

In addition to their roles in plant development, DELLA proteins are believed to differentially affect responses to infections by biotrophic or necrophic pathogens through their influence on the salicylic acid - jasmonic acid balance in Arabidopsis [5]. Similar claims were also made recently for wheat and barley by investigating DELLA-producing $R h t$ genes in these species [6]. The possibility that DELLA genes may play a critical role in disease resistance could drastically impact the efforts of cereal breeding as it could further restrict the options breeders have in exploiting the limited numbers of useful $R h t$ genes in each of these crop species. Many previous studies show that Rht genes, which may or may not produce DELLA proteins, co-locate with QTL conferring Fusarium head blight (FHB) and Fusarium crown rot (FCR) resistance [7-9]. 
Considering that accurate assessments for both FCR [10] and FHB [7] are difficult and that resistances to these diseases can be affected by many characteristics including plant height [11,12] and growth rate [13] which often segregate in populations used for QTL mapping, it is not difficult to understand why not all plant height QTL are coincident with those for FHB or FCR susceptibility $[14,15]$.

As opposed to segregating populations where individuals have different genetic backgrounds as well as the disease resistance loci under investigation, differences between the two isolines for a given pair of NILs are often minimal apart from the targeted trait. Thus, assessing genetic effects of a particular gene/trait using NILs can, to a large degree, eliminate the interference of other genes. As a result, NILs are extensively used for analysing effects of a wide array of traits including possible effects of plant height on FHB and FCR. These studies have shown that all $R h t$ genes, including those non-GAresponsive ones, affect FHB [11,15-17] and FCR $[12,18]$ resistance in wheat. These results seem to suggest that the effects of plant height on these Fusarium diseases are unlikely related to DELLA genes. To further clarify if the effects of plant height on Fusarium resistance are related to DELLA genes, we generated several pairs of NILs for the non-GA-responsive semi-dwarfing gene $u z u$ in barley. Responses of these NILs to FCR infection are described in this paper.

\section{Results}

Development and assessment of near isogenic lines for the semi-dwarfing gene uzu With the use of the SSR marker HMV33, ten heterozygous plants were identified from the TX9425/Franklin population and five from the TX9425/Gairdner population. Similar to those individuals with homozygous Franklin or Gairdner alleles, all of the 15 heterozygous individuals were characterized as tall plants. However, each of these individuals produced both tall and dwarf progenies. The two isolines for each of the 15 pairs of NILs developed from these heterozygous individuals showed highly significant difference in height under both temperature regimes assessed (Figure 1). In the low temperature regime, the average plant height across the 15 dwarf isolines was $72.0 \mathrm{~cm}$ and the 15 tall isolines was $111.3 \mathrm{~cm}$ thus the $u z u$ gene reduced height by $35.2 \%$ on average. In the high temperature regime, the average plant height for the 15 dwarf isolines was $27.8 \mathrm{~cm}$ and the 15 tall isolines was $90.4 \mathrm{~cm}$ thus the $u z u$ reduced height by $69.3 \%$ on average. When compared with its effects in the low temperature regime, the average impact of the $u z u$ gene on plant height increased in the high temperature regime by $34.1 \%$ on average (Table 1 ).

Comparisons of genomic DNA sequences among the three parental genotypes used in the development of the

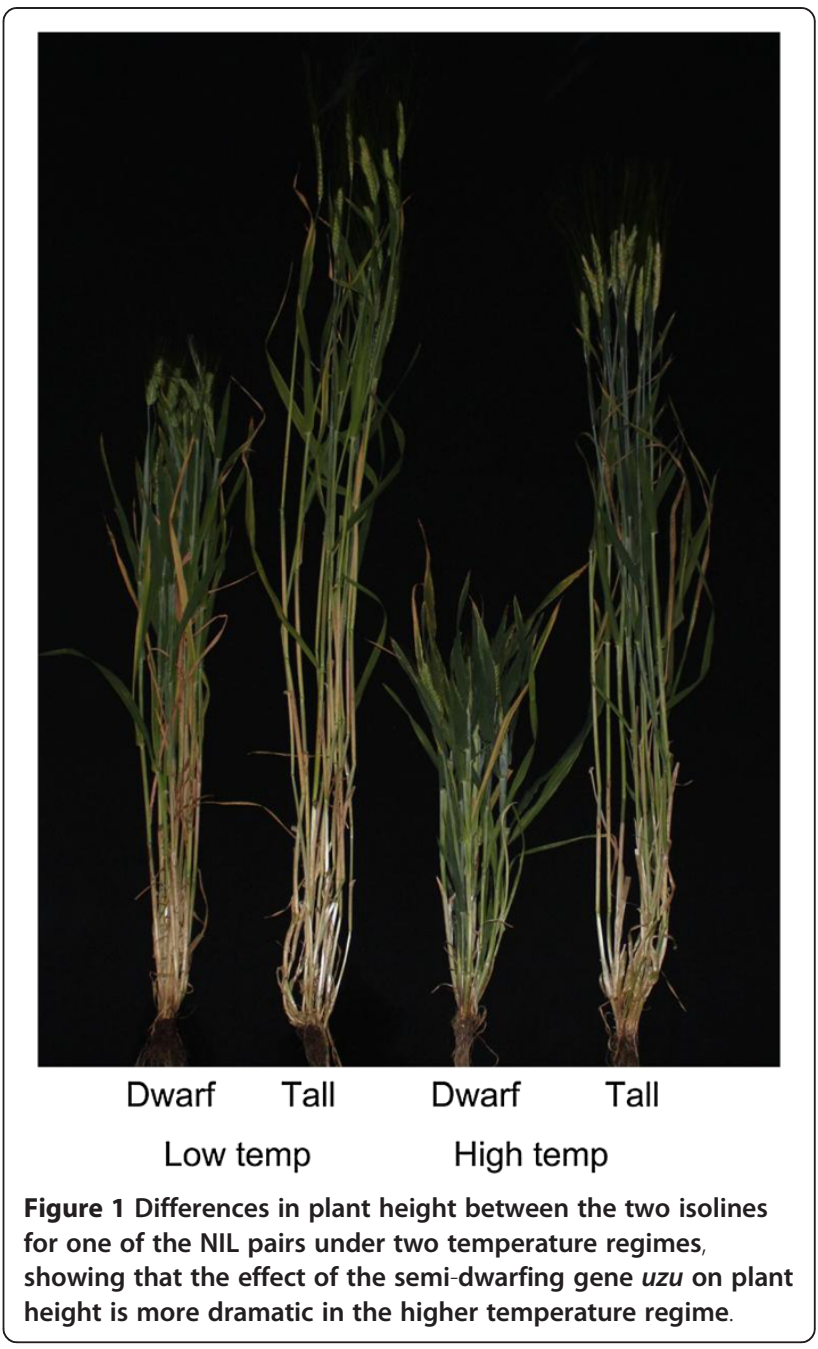

NILs confirmed the existence of the $u z u$ allele [19] in TX9425. The characteristic single-nucleotide A > G substitution of $u z u$ at the position 2612 was the only difference detected along the whole $u z u$ gene sequence among the three genotypes (Figure 2a). Analysis of the 15 pairs of NILs using the dCAP markers detected the expected $u z u$ allele from each of the $15 \mathrm{~d}$ warf isolines (Figure $2 \mathrm{~b}$ ).

\section{Differences in Fusarium crown rot severity among the NILs}

Difference in disease index (DI) between the two isolines was highly significant for each of the 15 pairs of NILs under both of the temperature regimes assessed. Similar to its impacts on plant height, the semi-dwarfing gene $u z u$ also showed larger effects on FCR severity in the high temperature regime than in the low temperature regime. In the low temperature regime, the average DI value across the 15 dwarfing isolines was 44.1 and that for the 15 tall isolines was 61.1, thus the $u z u$ gene reduced DI by $27.8 \%$ on average. In the high temperature regime, the average DI was 37.9 across the 15 dwarfing 
Table 1 Plant heights of 15 pairs of near isogenic lines for the barley dwarfing gene uzu under two different temperature regimes ${ }^{\#}$

\begin{tabular}{|c|c|c|c|c|c|c|c|}
\hline \multirow[t]{2}{*}{ Background } & \multirow[t]{2}{*}{ NIL } & \multicolumn{3}{|c|}{ Low temperature } & \multicolumn{3}{|c|}{ High temperature } \\
\hline & & Dwarf (cm) & Tall (cm) & Difference (\%) & Dwarf (cm) & Tall $(\mathrm{cm})$ & Difference (\%) \\
\hline \multirow[t]{5}{*}{ TX9425/ Gairdner } & NIL01 & $69.5 \pm 0.9$ & $114.3 \pm 1.8$ & $39.2 \pm 0.4^{* *}$ & $33.2 \pm 1.9$ & $84.8 \pm 1.2$ & $60.9 \pm 2.3^{* *}$ \\
\hline & NIL02 & $61.3 \pm 0.8$ & $113.3 \pm 1.9$ & $45.9 \pm 1.4^{* *}$ & $17.1 \pm 0.3$ & $82.7 \pm 2.2$ & $79.3 \pm 0.9^{* *}$ \\
\hline & NIL03 & $60.8 \pm 3.7$ & $104.7 \pm 4.9$ & $41.9 \pm 2.3^{* *}$ & $20.2 \pm 0.8$ & $88.8 \pm 1.3$ & $77.3 \pm 0.9^{* *}$ \\
\hline & NIL04 & $70.7 \pm 5.4$ & $107.5 \pm 2.1$ & $34.3 \pm 5.7^{* *}$ & $26.8 \pm 1.2$ & $89.4 \pm 1.5$ & $70.0 \pm 1.3^{* *}$ \\
\hline & NIL05 & $65.4 \pm 2.6$ & $107.3 \pm 2.7$ & $39.0 \pm 2.5^{* *}$ & $25.7 \pm 1.1$ & $96.5 \pm 2.4$ & $73.4 \pm 1.7^{* *}$ \\
\hline \multirow[t]{10}{*}{ TX9425/ Franklin } & NIL06 & $77.3 \pm 1.6$ & $108.5 \pm 2.0$ & $28.8 \pm 2.3^{* *}$ & $27.9 \pm 2.5$ & $92.8 \pm 2.3$ & $69.9 \pm 2.7^{* *}$ \\
\hline & NIL07 & $75.0 \pm 0.7$ & $119.5 \pm 3.7$ & $37.2 \pm 1.8^{* *}$ & $25.0 \pm 3.2$ & $88.1 \pm 2.3$ & $71.7 \pm 2.8^{* *}$ \\
\hline & NIL08 & $75.0 \pm 0.6$ & $123.0 \pm 1.7$ & $39.1 \pm 0.5^{* *}$ & $29.7 \pm 2.5$ & $98.6 \pm 7.3$ & $69.7 \pm 4.4^{* *}$ \\
\hline & NIL09 & $73.2 \pm 3.3$ & $117.3 \pm 1.6$ & $37.7 \pm 2.2^{* *}$ & $24.9 \pm 4.1$ & $75.3 \pm 2.4$ & $66.9 \pm 5.7^{* *}$ \\
\hline & NIL10 & $76.1 \pm 1.1$ & $114.6 \pm 0.7$ & $33.6 \pm 0.8^{* *}$ & $31.8 \pm 1.4$ & $89.3 \pm 1.9$ & $64.5 \pm 1.7^{* *}$ \\
\hline & NIL11 & $76.5 \pm 1.6$ & $104.9 \pm 3.1$ & $27.1 \pm 1.6^{* *}$ & $31.0 \pm 2.6$ & $96.6 \pm 2.6$ & $67.9 \pm 2.9^{* *}$ \\
\hline & NIL12 & $79.4 \pm 0.8$ & $109.5 \pm 2.7$ & $27.4 \pm 2.4^{* *}$ & $33.8 \pm 2.5$ & $98.1 \pm 2.1$ & $65.6 \pm 1.9^{* *}$ \\
\hline & NIL13 & $74.1 \pm 1.3$ & $112.3 \pm 1.7$ & $34.0 \pm 1.6^{* *}$ & $30.1 \pm 1.4$ & $93.9 \pm 2.1$ & $68.0 \pm 1.2^{* *}$ \\
\hline & NIL14 & $78.8 \pm 2.1$ & $106.2 \pm 2.6$ & $25.7 \pm 3.1^{* *}$ & $31.1 \pm 2.7$ & $89.8 \pm 1.8$ & $65.2 \pm 3.3^{* *}$ \\
\hline & NIL15 & $66.7 \pm 0.6$ & $106.6 \pm 0.7$ & $37.5 \pm 0.8^{* *}$ & $28.6 \pm 0.6$ & $91.0 \pm 2.6$ & $68.6 \pm 0.9^{* *}$ \\
\hline
\end{tabular}

\#: ‘*'indicate significant level at $p<0.01$.

isolines and was 55.8 across the 15 tall isolines thus the $u z u$ gene reduced DI by $31.7 \%$ on average (Table 2 ).

A trend similar to that based on DI values was observed when FCR severity was assessed by estimated biomasses of the Fusarium pathogen. The difference between the two isolines was highly significant for each of the 15 pairs of NILs assessed under both of the temperature regimes. The $u z u$ allele reduced Fusarium biomass by $7.8 \%$ and $9.5 \%$, respectively, on average across the 15 pairs of NILs in the low and high temperature regimes when Tri5 was used as the reference gene (Additional file 1: Figure S1). When $18 s$ was used as the reference gene, the $u z u$ gene reduced Fusarium biomass on average by $10.1 \%$ and $12.5 \%$, respectively, across the 15 pairs of NILs in the low and high temperature regimes (Additional file 2: Figure S2). Differences in Fusarium biomass between the two isolines for each of the 15 pairs of NILs were significantly larger in the high temperature regime when compared with those in the low temperature regime based on the use of either Tri5 (Figure 3a) or $18 s$ (Figure 3b).

\section{(a)}

TX9425: 2590- AGACCATTGGCAAGATCAAACGCCGCAACCTTGTTCCGCTC -2630 Franklin: 2590- AGACCATTGGCAAGATCAAACACCGCAACCTTGTTCCGCTC -2630 Gairdner: 2590- AGACCATTGGCAAGATCAAACACCGCAACCTTGTTCCGCTC -2630

(b)

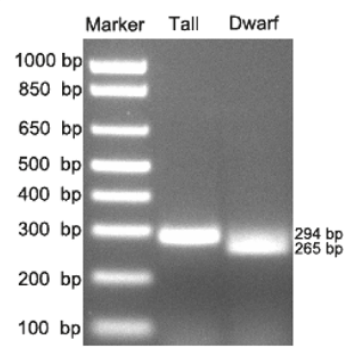

Figure 2 The characteristic single-nucleotide A > G substitution at the position 2612 in the uzu gene was present in TX9425 (a); and dCAPS anlysis of the uzu allele against one pair of NILs (b). 
Table 2 Disease index (DI) of 15 pairs of near isogenic lines for the barley dwarfing gene uzu under two different temperature regimes"

\begin{tabular}{|c|c|c|c|c|c|c|c|}
\hline \multirow[t]{2}{*}{ Background } & \multirow[t]{2}{*}{ NIL } & \multicolumn{3}{|c|}{ Low temperature } & \multicolumn{3}{|c|}{ High temperature } \\
\hline & & Dwarf $(\mathrm{cm})$ & Tall $(\mathrm{cm})$ & Difference (\%) & Dwarf $(\mathrm{cm})$ & Tall (cm) & Difference (\%) \\
\hline \multirow[t]{5}{*}{ TX9425/ Gairdner } & NIL01 & $43.8 \pm 2.6$ & $62.5 \pm 3.3$ & $30.0 \pm 1.0^{* *}$ & $41.8 \pm 1.0$ & $60.8 \pm 2.9$ & $31.2 \pm 2.0^{* *}$ \\
\hline & NIL02 & $37.8 \pm 1.3$ & $56.8 \pm 1.0$ & $33.5 \pm 1.6^{* *}$ & $31.8 \pm 1.9$ & $54.0 \pm 2.2$ & $41.2 \pm 1.3^{* *}$ \\
\hline & NIL03 & $38.3 \pm 1.5$ & $55.8 \pm 1.5$ & $31.4 \pm 1.2^{* *}$ & $31.8 \pm 1.0$ & $51.3 \pm 1.7$ & $38.0 \pm 1.6^{* *}$ \\
\hline & NIL04 & $46.8 \pm 2.9$ & $66.5 \pm 3.4$ & $29.7 \pm 2.2^{* *}$ & $41.8 \pm 1.3$ & $62.5 \pm 1.9$ & $33.2 \pm 0.9^{* *}$ \\
\hline & NIL05 & $59.0 \pm 2.1$ & $87.3 \pm 2.2$ & $32.4 \pm 0.9^{* *}$ & $48.0 \pm 1.4$ & $78.3 \pm 1.3$ & $38.7 \pm 1.3^{* *}$ \\
\hline \multirow[t]{10}{*}{ TX9425/ Franklin } & NIL06 & $58.8 \pm 1.7$ & $72.3 \pm 1.7$ & $18.6 \pm 0.8^{* *}$ & $49.5 \pm 1.7$ & $68.2 \pm 2.2$ & $27.5 \pm 1.0^{* *}$ \\
\hline & NIL07 & $40.0 \pm 1.4$ & $56.8 \pm 1.7$ & $29.5 \pm 2.2^{* *}$ & $36.0 \pm 1.6$ & $52.5 \pm 3.1$ & $31.3 \pm 3.0^{* *}$ \\
\hline & NIL08 & $52.5 \pm 1.9$ & $69.3 \pm 1.7$ & $24.2 \pm 1.1 * *$ & $40.5 \pm 1.3$ & $57.5 \pm 1.3$ & $29.5 \pm 2.7^{* *}$ \\
\hline & NIL09 & $34.0 \pm 1.6$ & $48.3 \pm 2.2$ & $29.5 \pm 1.3^{* *}$ & $32.8 \pm 1.0$ & $45.3 \pm 1.3$ & $27.6 \pm 0.9^{* *}$ \\
\hline & NIL10 & $36.3 \pm 2.1$ & $51.3 \pm 3.3$ & $29.2 \pm 1.2^{* *}$ & $33.3 \pm 1.3$ & $48.5 \pm 1.9$ & $31.4 \pm 1.8^{* *}$ \\
\hline & NIL11 & $36.8 \pm 2.9$ & $50.8 \pm 3.3$ & $27.6 \pm 1.6^{* *}$ & $33.3 \pm 2.0$ & $46.3 \pm 1.9$ & $28.1 \pm 1.9^{* *}$ \\
\hline & NIL12 & $38.3 \pm 1.7$ & $53.8 \pm 2.6$ & $28.8 \pm 1.4^{* *}$ & $35.0 \pm 1.8$ & $51.3 \pm 1.3$ & $31.7 \pm 2.3^{* *}$ \\
\hline & NIL13 & $34.3 \pm 2.2$ & $47.8 \pm 3.1$ & $28.3 \pm 0.8^{* *}$ & $31.5 \pm 1.0$ & $44.3 \pm 1.7$ & $28.8 \pm 1.3^{* *}$ \\
\hline & NIL14 & $42.3 \pm 1.5$ & $52.3 \pm 1.7$ & $19.1 \pm 1.4^{* *}$ & $36.3 \pm 0.9$ & $48.8 \pm 1.3$ & $25.6 \pm 2.2^{* *}$ \\
\hline & NIL15 & $63.0 \pm 1.6$ & $84.3 \pm 2.2$ & $25.2 \pm 0.8^{* *}$ & $45.3 \pm 2.8$ & $67.0 \pm 4.5$ & $32.4 \pm 0.9^{* *}$ \\
\hline
\end{tabular}

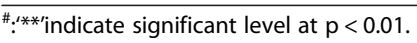

\section{Correlation between Fusarium crown rot severity and plant height}

Plant height was significantly and positively correlated with FCR severity. When FCR severity was measured with DI, the correlation coefficients were 0.64 and 0.73 for data obtained from the low and the high temperature regimes, respectively. When pathogen biomass was used in measuring FCR severity, the correlation coefficients were 0.56 and 0.53 for the low and high temperature regimes, respectively, when Tri5 was used as the reference gene. The correlation coefficients were 0.67 and 0.57 for the two different temperature regimes, respectively, when $18 s$ was used as the reference gene (Table 3 ).

\section{Discussion}

The possibility that DELLA genes could play a critical role in disease resistance in cereals [6] could seriously restrict options breeders may have in exploiting the limited numbers of useful $R h t$ genes in wheat or barley. To further investigate this possibility, we generated 15 pairs of NILs for the semi-dwarfing barley gene $u z u$. These NILs were assessed under two environments between which significant differences in plant height between the two isolines for a given pair of NILs were detected. Highly significant difference in FCR resistance was detected between the two isolines for each of the NIL pairs and the magnitudes of the differences in FCR resistance are associated with the magnitudes of differences in plant height. It is known that the semi-dwarfism conferred by $u z u$ is not due to changed sensitivity to GA but to brassinosteroids $[19,20]$. Thus, the results from this study showed that plant height affects FCR resistance in barley and that the height effects are unlikely related to DELLA genes but due to direct or indirect effects of height difference per se.

Results from previous studies also show that all $R h t$ genes, including those non-GA-responsive ones, affect FCR in wheat $[12,18]$. There is no 'cause-and-effect' that can be implied at this stage yet. However, one of the possible explanations for the reduced FCR severities of the dwarf isolines in both wheat and barley could be their increased cell densities. Considering that FCR is measured by the speed of disease spread within the infected tissues [21,22], the increased cell densities of dwarfing lines $[23,24]$ could form increased physical barriers to pathogen spread within infected tissues. This explanation is supported by the findings that treating plants with exogenous GA increased CR severity as well as seedling lengths in all of the isolines tested, and that the better resistance of the dwarf isolines did not seem to be related to enhanced induction of defense genes [12]. It is known that the growth response of wheat seedlings to exogenous GA application is due to cell expansion not cell division $[25,26]$. Further evidence supporting the explanation that the increased cell density is likely a contributing factor to the reduced FCR severity is that slow growing genotypes tend to give better CR resistance [13]. It is well known that the genetic control of growth rate is complex and can be conditioned by multiple genes including those for vernalization, photoperiod 

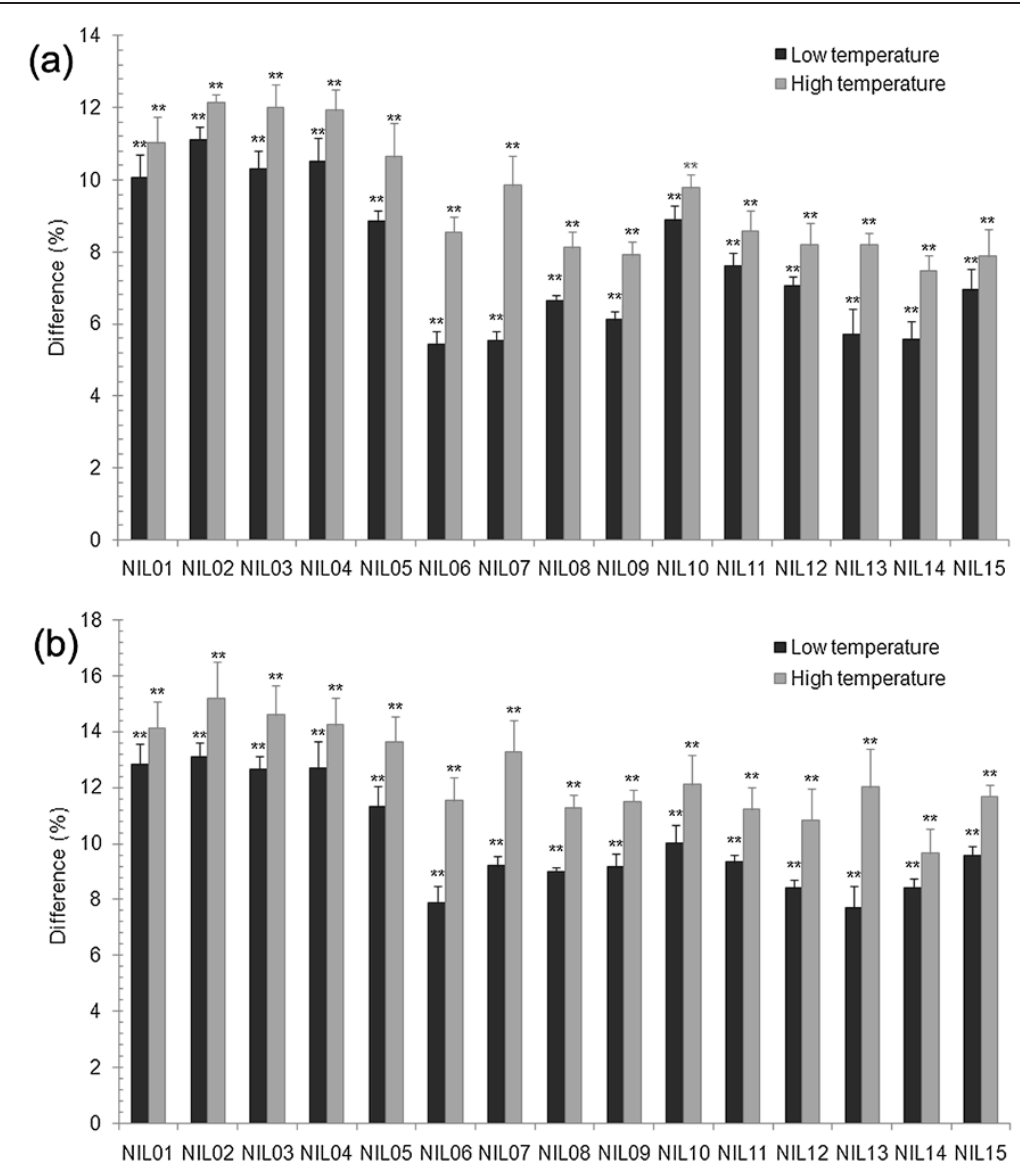

Figure 3 Differences in Fusarium biomass for the 15 pairs of NILs assessed between the two temperature regimes with Tri5 (a) or $18 \mathrm{~s}$ (b) as the reference gene. ${ }^{\prime * *}$ indicate significant level at $\mathrm{p}<0.01$.

responses as well as those independent of vernalization and day-length [27]. Nevertheless, it is not unreasonable to speculate that, when compared with those quick growing genotypes, stem elongation of those slow growing genotypes is slower thus their cell densities at stem bases would stay higher for a longer period of time [12].

\section{Conclusion}

By generating and investigating several pairs of NILs for a non-GA-responsive $R h t$ gene, we demonstrated in this study that the observed effects of plant height on FCR resistance are not related to DELLA genes in barley. These results agree well with previous data on both FCR

Table 3 Correlation coefficients between FCR severity and plant height ${ }^{\#}$

\begin{tabular}{|c|c|c|c|c|c|c|c|c|c|}
\hline \multirow[t]{2}{*}{ Condition } & \multirow[t]{2}{*}{ Parameter ${ }^{*}$} & \multicolumn{4}{|c|}{ Low temperature } & \multicolumn{4}{|c|}{ High temperature } \\
\hline & & $\mathrm{PH}$ & DI & Tri5 & $18 \mathrm{~s}$ & $\mathrm{PH}$ & DI & Tri5 & $18 \mathrm{~s}$ \\
\hline \multirow[t]{4}{*}{ Low temperature } & $\mathrm{PH}$ & 1.00 & & & & & & & \\
\hline & $\mathrm{Dl}$ & $0.64^{* *}$ & 1.00 & & & & & & \\
\hline & Tri5 & $0.56^{*}$ & $0.67^{* *}$ & 1.00 & & & & & \\
\hline & $18 \mathrm{~s}$ & $0.67^{* *}$ & $0.66^{* *}$ & $0.94^{* *}$ & 1.00 & & & & \\
\hline \multirow[t]{4}{*}{ High temperature } & $\mathrm{PH}$ & $0.57^{*}$ & 0.38 & 0.35 & 0.40 & 1.00 & & & \\
\hline & DI & $0.72^{* *}$ & $0.73^{* *}$ & $0.76^{* *}$ & $0.75^{* *}$ & $0.73^{* *}$ & 1.00 & & \\
\hline & Tri5 & $0.61^{*}$ & $0.68^{* *}$ & $0.88^{* *}$ & $0.91^{* *}$ & $0.53^{*}$ & $0.80^{* *}$ & 1.00 & \\
\hline & $18 \mathrm{~s}$ & $0.77^{* *}$ & $0.74^{* *}$ & $0.79 * *$ & $0.88^{* *}$ & $0.57^{*}$ & $0.81^{* *}$ & $0.95^{* *}$ & 1.00 \\
\hline
\end{tabular}

${ }^{\star *}: \mathrm{PH}=$ plant height; $\mathrm{DI}=$ disease index; Tri5 = Fusarium biomass assessed using Tri5 as the fungal reference gene; $18 \mathrm{~s}=$ Fusarium biomass assessed using $18 \mathrm{~s}$ as the fungal reference gene. ${ }^{\#:}{ }^{* * \prime}$ and ${ }^{\prime * \prime}$ indicate significant levels at $p<0.01$ and $p<0.05$, respectively. 
and FHB in wheat showing overwhelmingly that the observed effects of plant height on resistances to FCR or FHB can be explained by direct or indirect effects of plant height difference per se. Results from the interactions between $R h t$ loci and Fusarium resistance highlight the importance of understanding the possible relationships between resistance and other traits of agronomic importance. It is critical to understand that the value of a resistance gene in breeding programs could be compromised if it dramatically affects plant development and morphology. The effects of Rht genes on Fusarium diseases described in this paper showed specifically that caution should be taken when considering exploiting any of the numerous FHB or FCR resistance loci colocating with $R h t$ genes in wheat or barley.

\section{Methods}

Development of near isogenic lines (NILs) for the barley dwarfing gene uzu

NILs for the semi-dwarfing gene $u z u$ were developed from two $F_{2}$ populations, TX9425/Franklin and TX9425/ Gairdner. The co-dominant SSR marker HVM33 [28], which was most closely linked to the peak of the QTL of dwarfing gene $u z u$, was used to select heterozygous individuals from these populations following the method as described by Chen et al. [28]. The selected heterozygous individuals were selfed and the process of selecting heterozygous individuals and selfing was repeated until the $F_{8}$ generation following the 'fast generation' procedure described by Zheng et al. [29]. Two homozygous lines, one with and the other without the $u z u$ allele, were then isolated from the progeny of each of the $\mathrm{F}_{8}$ heterozygous plants and were treated as a pair of NILs.

\section{Confirmation of the uzu allele by molecular cloning}

Leaf samples from TX9425, Franklin and Gairdner were collected 4 weeks after germination and frozen immediately in liquid nitrogen and stored in a $-80^{\circ} \mathrm{C}$ freezer until processing. Frozen samples were ground in a Retsch MM300 Ball mill (Retsch GmbH, Haan, Germany) and approximately $5 \mathrm{mg}$ was used for DNA extraction. DNA was extracted using the QIAGEN plant DNeasy extraction kit (Catalogue number 69103; http://www.qiagen.com) following the manufacturer's protocol with a final elution volume of $200 \mu \mathrm{L}$. PCR was performed in $20 \mu \mathrm{L}$ reactions containing 1-10 ng genomic DNA, 5 pmol of each primer (Additional file 3: Table S1), $200 \mu \mathrm{M}$ deoxyribonucleotides, $1.5 \mathrm{mM} \mathrm{MgCl}_{2}, 50 \mathrm{mM} \mathrm{KCl}, 10 \mathrm{mM}$ Tris-Cl pH 9.0, $0.1 \%$ Triton X-100 and 2 units of Taq polymerase. Cycling conditions were: $94^{\circ} \mathrm{C}$ for $5 \mathrm{~min}$, followed by 35 cycles at $94^{\circ} \mathrm{C}$ for $45 \mathrm{~s}$, the appropriate annealing temperature (Additional file 3: Table S1) for $45 \mathrm{~s}$, and $72^{\circ} \mathrm{C}$ for $1 \mathrm{~min}$, with a final extension at $72^{\circ} \mathrm{C}$ for an additional $15 \mathrm{~min}$. Amplification products were extracted from
1.5\% agarose gels using QIAquick Extraction Kit (QIAGEN) and cloned into a TOPO vector (Invitrogen). The transformed competent cells $E$. coli were incubated at $37^{\circ} \mathrm{C}$ on an LB medium containing Blue-White Select Screening Reagent (Sigma) overnight. Three white colonies for each insert were selected and transferred into a liquid LB medium for plasmid isolation. Plasmid purification was carried out using QIAprep Spin Miniprep Kit (QIAGEN). The inserts were sequenced by Australian Genome Research Facility Ltd.

Derived cleaved amplified polymorphic sequence (dCAPS) anlysis of the uzu allele in the near isogenic lines (NILs) To detect the presence or absence of the $u z u$ allele in the NILs, dCAPS method was performed as described by Michaels and Amasino [30]. Genomic DNAs from the NILs were amplified using the following primers: forward 5'- GAAATGGAGACCATTGGCAAGATCAAGC -3' and reverse 5'- CCTTGCCTCCAGATTCTCATCAAC -3'. PCR was performed in $20 \mu \mathrm{L}$ reactions containing 1-10 ng genomic DNA, 5 pmol of each primer, $200 \mu \mathrm{M}$ deoxyribonucleotides, $1.5 \mathrm{mM} \mathrm{MgCl}_{2}, 50 \mathrm{mM} \mathrm{KCl}, 10 \mathrm{mM}$ Tris-Cl $\mathrm{pH}$ 9.0, 0.1\% Triton X-100 and 2 units of Taq polymerase. Cycling conditions were: $94^{\circ} \mathrm{C}$ for $5 \mathrm{~min}$, followed by 35 cycles at $94^{\circ} \mathrm{C}$ for $45 \mathrm{~s}, 55^{\circ} \mathrm{C}$ for $45 \mathrm{~s}$ and $72^{\circ} \mathrm{C}$ for $1 \mathrm{~min}$, with a final extension at $72^{\circ} \mathrm{C}$ for an additional $15 \mathrm{~min}$. PCR products were digested with the restriction enzyme HhaI by adding $10 \mu \mathrm{L}$ of PCR product to $10 \mu \mathrm{L}$ of the appropriate $1 \times$ buffer containing 2 units of HhaI. The reactions were incubated at $37^{\circ} \mathrm{C}$ for $8 \mathrm{~h}$. After digestion, $10 \mu \mathrm{L}$ of the reaction was analyzed for DNA fragment length on $3 \%$ agarose gels.

\section{Measurement of plant height}

Plant heights of the NILs were assessed in four trials in controlled environment cabinets in CSIRO Brisbane laboratories. Each of the trials consisted of two replicates. Three plants, each in a different $2.0 \mathrm{~L}$ pot, were used in each of the replicates. For each trial, the pots were arranged in a randomized complete block design. The trials were conducted under two different temperature regimes. Settings for the low temperature regime were $22 / 16( \pm 1)^{\circ} \mathrm{C}$ day/night temperature and $65 / 90( \pm 5) \%$ day/night relative humidity. The settings for the high temperature regime were $28 / 20$ $( \pm 1)^{\circ} \mathrm{C}$ day/night temperature and $65 / 90( \pm 5) \%$ day/night relative humidity. A 14-hour photoperiod with $500 \mu \mathrm{mol}$ $\mathrm{m}^{-2} \mathrm{~s}^{-1}$ photon flux density at the level of the plant canopy was used for all of the trials. Plant heights were measured using the two tallest tillers for each plant and their averages were used in statistical analysis.

\section{Fusarium crown rot assessment}

The assessment of FCR was conducted using F. pseudograminearum isolate CS3096. This isolate is highly 
aggressive based on an assessment of over 650 isolates collected in field surveys from Queensland and New South Wales [31]. Fungal inoculum was prepared following the method described by Li et al. [22]. The spores were harvested and the concentration of macroconidial suspension was adjusted to $1 \times 10^{6}$ spores $/ \mathrm{ml}$. Tween 20 was added to the spore suspension to a final concentration of $0.1 \% \mathrm{vol} /$ vol prior to use for inoculation. Seeds were germinated in Petri dishes on three layers of filter paper saturated with water. The germinated seeds were immersed in the spore suspension for $1 \mathrm{~min}$ and two seedlings were planted into a $5 \mathrm{~cm}$ square punnet (Rite Grow Kwik Pots, Garden City Plastics, Australia) containing sterilized University of California mix C (50\% sand and $50 \%$ peat v/v). The punnets were arranged in a randomized block design. To promote FCR development, water-stress was applied during the FCR assessment. Inoculated seedlings were watered only when wilt symptoms appeared.

Four independent trials were conducted in assessing FCR severity. Each of the trials contained two replicates, each replicate with ten seedlings. FCR severity was scored using a ' $0-5$ ' scale as described by Li et al. [22], where ' 0 ' representing no symptom and ' 5 ' whole seedling completely necrotic. A disease index (DI) was then calculated for each line following the formula of DI $=\sum\left(\mathrm{R}_{\mathrm{nX}} / 5 \mathrm{~N}\right) \times$ 100 , where $X$ is the scale value of each plant, $n$ is the number of plants in the category, and $\mathrm{N}$ is the total number of plants assessed for each line.

\section{Assessment of fungal biomass by quantitative polymerase chain reaction (qPCR)}

To analyse fungal biomass, tissue samples were collected 4 weeks after inoculation by removing the lower $2 \mathrm{~cm}$ of the seedling base of all 10 seedlings in a replication. The collected samples were immediately immersed in liquid nitrogen and then stored in a $-80^{\circ} \mathrm{C}$ freezer until processing. Frozen samples were ground in a Retsch MM300 Ball mill (Retsch $\mathrm{GmbH}$, Haan, Germany) and approximately $5 \mathrm{mg}$ was used for DNA extraction. Mycelium of F. pseudograminearum and disease free barley tissue in a CEF were similarly ground and used as controls. The ground samples were stored at $-20^{\circ} \mathrm{C}$ until DNA extraction.

DNA was extracted using the QIAGEN plant DNeasy extraction kit (Doncaster, Victoria, Australia) following the manufacturer's protocol with a final elution volume of $200 \mu \mathrm{L}$. Fungal biomass was determined by qPCR as the proportion of barley DNA to fungal DNA with barley actin (AY145451) as the reference gene (forward 5'GAACAGGAGCTGGAGACTGC-3' and reverse 5'-ATC ATGGATGGCTGGAAGAG-3'). Two reference genes were used for estimating fungal biomass. One was the fungal ribosomal $18 \mathrm{~s}$ gene (forward 5'-GTCCGGCC GGGCCTTTCC-3' and reverse 5'AAGTCCTGTTTC CCCGCCACGC-3') and the other was the Tri5 gene (forward 5'-GCGCATCGAGAATTTGCA-3'; reverse 5'TGGCGAGGCTGAGCAAAG-3'). Both $18 \mathrm{~s}$ and Tri5 have previously been used in estimating Fusarium biomass in barley and wheat FCR [32].

The volume used for qPCR amplification was $10 \mu \mathrm{L}$ containing $5 \mu \mathrm{L}$ SYBR Green PCR master mix (Applied Biosystems, Scoresy, Victoria, Australia), $1 \mu \mathrm{L}$ of a $3 \mathrm{mM}$ mix of forward and reverse primers, and $4 \mu \mathrm{L}$ of sample DNA diluted 1:10 in sterile milliQ water. Following an initial denaturation at $95^{\circ} \mathrm{C}$ for $10 \mathrm{~min}, 45$ cycles each of $15 \mathrm{~s}$ denaturing at $95^{\circ} \mathrm{C}$ and $1 \mathrm{~min}$ annealing/elongation step at $60^{\circ} \mathrm{C}$ were used in qPCR. A final denaturation step at $95^{\circ} \mathrm{C}$ for $2 \mathrm{~min}$, annealing at $60^{\circ} \mathrm{C}$, and denaturing at $95^{\circ} \mathrm{C}$ for $15 \mathrm{~s}$ was added to determine the melting temperature of the amplified product in the form of a dissociation curve. qPCR was performed on 384 well plates, each DNA extract (biological replication) was analysed in three replicated wells for each pair of primers. The average value from the three replicated wells was used as data for each biological replication. Fusarium DNA relative to barley DNA was calculated as an estimate of relative biomass using the following equation [33]:

$$
\text { Relative biomass }=\frac{\mathrm{Ef}_{\text {Fungal }}^{-\mathrm{Ct}}}{\mathrm{Ef}_{\text {Plant }}^{-\mathrm{Ct}}}
$$

where Ef is PCR amplification efficiency determined using LINREGPCR 7.5 [34] and Ct is the crossing threshold.

\section{Statistical analyses}

Statistical analyses were performed using the SPSS statistics 17.0 for Windows (SPSS Inc., Chicago, IL). For each trial, the following mixed-effect model was used: $\mathrm{Yij}=\mu+r i+g j+w i j$. Where: $\mathrm{Y} i j=$ trait value on the $j$ th genotype in the $i$ th replication; $\mu=$ general mean; $r i=$ effect due to $i$ th replication; $g j=$ effect due to the $j$ th genotype; $w i j=$ error or genotype by replication interaction, where genotype was treated as a fixed effect and that of replicate as random. Pearson correlation coefficients were estimated between plant height, DI value and Fusarium biomass.

\section{Additional files}

\footnotetext{
Additional file 1: Figure S1. Relative biomass of Fusarium between the two isolines for each of the 15 pairs of NILs under the low - (a) and high - temperature (b) regimes with Tri5 as the reference gene.

Additional file 2: Figure S2. Relative biomass of Fusarium between the two isolines for each of the 15 pairs of NILs under the low - (a) and high - temperature (b) regimes with $18 \mathrm{~s}$ as the reference gene.

Additional file 3: Table S1. Primer sequences used for uzu allele detection.
}

\section{Competing interests}

The authors declare that they have no competing interests. 


\section{Authors' contributions}

$C L, J M M, Y-L Z, M Z$ and $Y W$ conceived and designed the experiments. GC and $C L$ developed the near isogenic lines. GC and WY contributed to the Fusarium crown rot assessment. GC and YL performed the gene cloning, dCAPS and $\mathrm{qPCR}$ analysis. GC, YL and $\mathrm{CL}$ analyzed the data. $\mathrm{CL}, \mathrm{GC}, \mathrm{JMM}$, Y-LZ, MZ and YW wrote the manuscript. All the authors read and approved the final manuscript.

\section{Acknowledgements}

GC acknowledges the China Scholarship Council for funding his visit to CSIRO Plant Industry. The authors also wish to thank Caritta Eliasson, Paul Melloy and Friday Obanor for their technical assistance. Funding support from the Grains Research and Development Corporation, Australia, is gratefully acknowledged.

\section{Author details}

'CSIRO Plant Industry, 306 Carmody Road, St Lucia QLD 4067 Australia. ${ }^{2}$ Triticeae Research Institute, Sichuan Agricultural University, Wenjiang, Chengdu 611130, China. ${ }^{3}$ Institute of Ecological and Environmental Sciences, Sichuan Agricultural University, Wenjiang, Chengdu 611130, China. ${ }^{4}$ Institute of Food Crops, Jiangsu Academy of Agricultural Science, 50 Zhongling Street, Nanjing 210014, China. ${ }^{5}$ Tasmanian Institute of Agriculture and School of Agricultural Science, University of Tasmania, P.O. Box 46, Kings Meadows, Tasmania 7250, Australia. ${ }^{6}$ School of Plant Biology, The University of Western Australia, Perth, WA 6009, Australia.

Received: 27 November 2013 Accepted: 8 January 2014 Published: 13 January 2014

\section{References}

1. Richards RA: The effect of dwarfing genes in spring wheat in dry environments I. Agronomic characteristics. Aust J Agr Res 1992, 43:517-527.

2. Ellis MH, Rebetzke GJ, Azanza F, Richards RA, Spielmeyer W: Molecular mapping of gibberellin-responsive dwarfing genes in bread wheat. Theor Appl Genet 2005, 111:423-430.

3. Peng JR, Richards DE, Hartley NM, Murphy GP, Devos KM, Flintham JE, Beales J, Fish LJ, Worland AJ, Pelica F, Sudhakar D, Christou P, Snape JW, Gale MD, Harberd NP: 'Green revolution' genes encode mutant gibberellin response modulators. Nature 1999, 400:256-261.

4. Gasperini D, Greenland A, Hedden P, Dreos R, Harwood W, Griffiths S: Genetic and physiological analysis of Rht8 in bread wheat: an alternative source of semi-dwarfism with a reduced sensitivity to brassinosteroids. J Exp Bot 2012, 63:4419-4436

5. Navarro L, Bari R, Achard P, Lison P, Nemri A, Harberd NP, Jones JDG: DELLAs control plant immune responses by modulating the balance and salicylic acid signalling. Curr Biol 2008, 18:650-655.

6. Saville RJ, Gosman N, Burt CJ, Makepeace J, Steed A, Corbitt M, Chandler E, Brown JKM, Boulton MI, Nicholson P: The 'Green Revolution' dwarfing genes play a role in disease resistance in Triticum aestivum and Hordeum vulgare. J Exp Bot 2012, 63:1271-1283.

7. Buerstmayr H, Ban T, Anderson JA: QTL mapping and marker-assisted selection for Fusarium head blight resistance in wheat: a review. Plant Breed 2009, 128:1-26.

8. Li HB, Zhou MX, Liu CJ: A major QTL conferring crown rot resistance in barley and its association with plant height. Theor Appl Genet 2009, 118:903-910.

9. Chen GD, Liu YX, Wei YM, McIntyre CL, Zhou XZ, Zheng Y-L, Liu CJ: Major QTL for Fusarium crown rot resistance in a barley landrace. Theor Appl Genet 2013, 126:2511-2520

10. Yang XM, Ma J, Li HB, Ma HX, Yao JB, Liu CJ: Different genes can be responsible for crown rot resistance at different developmental stages of wheat and barley. Eur J Plant Path 2010, 128:495-502.

11. Yan W, Li HB, Cai SB, Ma HX, Rebetzke GJ, Liu CJ: Effects of plant height vary with type I and type II resistance of Fusarium head blight in wheat (Triticum aestivum L.). Plant Pathol 2011, 60:506-512.

12. Liu YX, Yang XM, Ma J, Wei YM, Zheng YL, Ma HX, Yao JB, Yan GJ, Wang YG, Manners JM, Liu CJ: Plant height affects Fusarium crown rot severity in wheat. Phytopathology 2010, 100:1276-1281.

13. Liu YX, Zheng YL, Wei YM, Zhou MX, Liu CJ: Genotypic differences in resistance to crown rot caused by Fusarium pseudograminearum in barley (Hordeum vulgare L.). Plant Breed 2012, 131:728-732.

14. Draeger R, Gosman N, Steed A, Chandler E, Thomsett M, Srinivasachary Schondelmaier J, Buerstmayr H, Lemmens M, Schmolke M, Mesterhazy A,
Nicholson P: Identification of QTLs for resistance to Fusarium head blight, DON accumulation and associated traits in the winter wheat variety Arina. Theor Appl Genet 2007, 115:617-625.

15. Srinivasachary, Gosman N, Steed A, Hollins TW, Bayles R, Jennings P, Nicholson PP: Semi-dwarfing Rht-B1 and Rht-D1 loci of wheat differ significantly in their influence on resistance to Fusarium head blight. Theor Appl Genet 2009, 118:695-702.

16. Hilton AJ, Jenkinson P, Hollins TW, Parry DW: Relationship between cultivar height and severity of Fusarium earl blight in wheat. Plant Pathol 1999, 56:264-276.

17. Miedaner T, Voss HH: Effect of dwarfing Rht genes on Fusarium head blight resistance in two sets of near-isogenic lines of wheat and check cultivars. Crop Sci 2008, 48:2115-2122.

18. Fu LY, Wang YG, Liu CJ: Rank regression for analysing ordinal qualitative data for treatment comparison. Phytopathology 2012, 102:1064-1070.

19. Saisho D, Tanno K, Chono M, Honda I, Kitano H, Takeda K: Spontaneous brassinolide-insensitive barley mutants 'uzu' adapted to East Asia. Breeding Sci 2004, 54:409-416.

20. Chono M, Honda I, Zeniya H, Yoneyama K, Saisho D, Takeda K, Takatsuto S, Hoshino T, Watanabe Y: A semidwarf phenotype of barley uzu results from a nucleotide substitution in the gene encoding a putative brassinosteroid receptor. Plant Physiol 2003, 133:1209-1219.

21. Mitter V, Zhang MC, Liu CJ, Ghosh R, Ghosh M, Chakraborty S: A high throughput glasshouse bioassay to detect crown rot resistance in wheat germplasm. Plant Pathol 2006, 55:433-441.

22. Li XM, Liu CJ, Chakraborty S, Manners JM, Kazan K: A simple method for the assessment of crown rot disease severity in wheat seedlings inoculated with Fusarium pseudograminearum. J Phytopathol 2008, 156:751-754.

23. Keyes GJ, Paolillo DJ, Sorrells ME: The effects of dwarfing genes Rht1 and Rht2 on cellular dimensions and rate of leaf elongation in wheat. Ann Bot 1989, 64:683-690.

24. Miralles DJ, Calderini DF, Pomar KP, D'Ambrogio A: Dwarfing genes and cell dimensions in different organs of wheat. J Exp Bot 1998, 49:1119-1127.

25. Jones RL: Gibberellins: their physiological role. Annu Rev Plant Physiol 1973, 24:571-598.

26. Wright STC: A sequential growth response to gibberelin acid, kinetin and indolyl-3-acetic acid in the wheat coleoptile (Triticum vulgare L.). Nature 1961, 190:699-700

27. Worland AJ, Gale MD, Law CN: Wheat genetics. In Wheat Breeding: its Scientific Basis. Edited by Lupton FGH. London/New York: Chapman and Hall Ltd; 1987:129-171.

28. Chen GD, Li HB, Zheng Z, Wei YM, Zheng YL, McIntyre CL, Zhou MX, Liu CJ: Characterization of a QTL affecting spike morphology on the long arm of chromosome $3 \mathrm{H}$ in barley (Hordeum vulgare $\mathrm{L}$.) based on near isogenic lines and a NIL-derived population. Theor Appl Genet 2012, 125:1385-1392.

29. Zheng Z, Wang HB, Chen GD, Yan GJ, Liu CJ: A procedure allowing up to eight generations of wheat and nine generations of barley per annum. Euphytica 2013, 191:311-316.

30. Michaels SD, Amasino RM: A robust method for detecting single-nucleotide changes as polymorphic markers by PCR. Plant J 1998, 14:381-385.

31. Akinsanmi OA, Mitter V, Simpfendorfer S, Backhouse D, Chakraborty S: Identity and pathogenicity of Fusarium spp. isolated from wheat fields in Queensland and northern New South Wales. Aust J Agr Res 2004, 55:97-107.

32. Liu YX, Ma J, Yan W, Yan GJ, Zhou MX, Wei YM, Zheng YL, Liu CJ: Different tolerance in bread wheat, durum wheat and barley to Fusarium crown rot disease caused by Fusarium pseudograminearum. J Phytopathol 2012, 160:412-417.

33. Yuan JS, Reed A, Chen F, Stewart CN: Statistical analysis of real-time PCR data. BMC Bioinforma 2006, 7:85.

34. Ramakers C, Ruijter JM, Deprez RHL, Moorman AFM: Assumption-free analysis of quantitative real-time polymerase chain reaction (PCR) data. Neurosci Lett 2003, 339:62-66.

doi:10.1186/1471-2229-14-22

Cite this article as: Chen et al:: The non-gibberellic acid-responsive semi-dwarfing gene uzu affects Fusarium crown rot resistance in barley. BMC Plant Biology 2014 14:22. 